Rev. Far. Meal vet. Zootec. Tniv. S. Paulo

$13(1): 241-47,1976$

\author{
OCORREACIA DE MIRORGANISMOS RESPONSÁVEIS PELA \\ DETERIORACÃO DE I $M$ PROIOUTO CÁRNEO DE BAIXA ACIIEZ
}

\author{
José Cezar PANETTA * \\ Omar Jaques Marzagão BARBUTO** \\ Raphael Valentino RICCETTI * \\ Arlindo GARCIA MORENO *
}

RFMV-A/16

\begin{abstract}
Panetta, J, C.; Barbuto, O. J. M.; Riccetti, R. V.; Garcia Moreno, A. Ocorrencia de microrganismos responsáveis pela deterioração de um produto cárneo de baixa acidez. Rev. Fac. Med. vet. Zootec. Univ. S. Paulo, 13(1):241-47, 1976
\end{abstract}

Resumo: Procurou-se identificar a causa mais comum da deterioração da presuntada enlatada, isto é, um sub-processamento ou um vazamento pós-processumento. Para tanto, foram escolhidos quatro grupos de germes: dois tipicamente esporulados (Bacillus e Clostridium), que refletem muito bem a deterioração por sub-processamento, e dois não esporulados (coliformes e enterococos), habitantes normais do intestino do homem e dos animais e, conseriüentemente, valiosos indices de contaminação por vazamentos da lata sanitária.

Analisudos 210 continentes, as porcentagens de ocorrência de positivos foram as seguintes: Bacillus - 6.66\% i Clostridium - 3,80\%; coliformes $9,52 \%$; enterococos - $15,71 \%$.

Os resultudos obtidos permitem responsubilizur os vazamentos eventualmente existentes nas latas sanitárias, como principais reponsáveis pelas alteraşōes putrefativas de natureza microbiana sofridas pelo alimento analisado.

Unitermos: Alimentos enlatados * Enlatados cárneos*; Enlutados, deterioraşa *; Deterioração.

\title{
INTRODUCAO, LITERATURA
}

E PROPOSICAO

Há décadas, tem sido o calor o agente mais largamente utilizado na preservação dos alimentos. Os enlatados tornaram-se tão comuns na dieta humana, que a saúde da população mundial depende agora, em larga escala, da qualidade desses alimentos, já que segundo HERSOM \& HUL-
LAND 9, englobando a opiniāo de numerosos autores, a deterioração microbiana dos alimentos enlatados processados pelo calor é causada por microrganismos que sobrevivem aos processos térmicos, ou que penetram através de vazamentos do recipiente, após o processamento pelo calor.

* Professior Assistente Doutor.

** Professor Livre Docente.

Departamento de Medicina Veterinária Preventiva e Saúde Animal da Faculdade de Medicina Veterinária e zootecnia da USP. 
i praticamente impossivel prever quais os tipos de microrganismos que poderāo penetrar nas latas, atraiés de um vazamento, devendo a indústria tomar medidas adequadas para evitar este tipo de deterioração microbiana e a resistência dos microrganismos ao calor estāo intimamente relacionados com a acidez dos alimentos enlatados. CAMERON \& ESTY"5 sugerem a seguinte classificação:

1. alimentos de acidez baixa - $\mathrm{pH} 5$ ou mais;

2. alimentos de acidez média - $\mathrm{pH} 5.0$ a 4.5 ;

3. alimentos ácidos - $\mathrm{pH} 4.5$ a 3.7 ;

4. alimentos de acidez alta -... $\mathrm{pH} 3.7$ ou menos.

A linha divisória entre os alimentos de acidez baixa e os alimentos ácidos é admitida por ALLEN 1 como sendo o valor de ${ }_{\mathrm{j}} \mathrm{H}$ igual a 4,5 , porque algumas linhagens de Clostridium botulinum podem crescer $\mathrm{e}$ produzir toxina em $\mathrm{pH}$ com valores tão baixos como 4,6. Alguns anaeróbios sacaroliticos altamente resistentes ao calor por exemplo o Clostridium thermosaccharolyticum - crescem e causam deterioração neste intervalo semi-ácido.

Para os alimentos ácidos e de baixa acidez, as bactérias que esporulam são de maior importância do ponto de vista da esterilização. FRAZIER ' classifica essas bactérias, segundo a demanda de oxigênio, em:
a) aeróbios estritos (Bucillus sp.);
b) anacróbios facultativos (Bucillus sp.);
c) anaeróbios estritos (Clostridium sp.).

Dos três grupos, segundo esse mesmo autor, o primeiro é o menos importante, já que engloba as espécies que requerem oxigênio molecular para o seu desenvolvimento. Com as atuais condições de enlalamento, a maioria dos alimentos contém niveis muitos baixos de oxigênio molecular. insuficientes para garantir um crescimento considerável. Além disso, os esporos da maioria dos aeróbios estritos tem haixa resistência ao calor, quando comparada com os esporos de numerosos microrganismos pertencentes aos outros dois grupos.

VAUGHN e col. ${ }^{17}$, ao considerarem o grupo dos anaeróbios facultativos, citam como importantes, para os alimentos ácidos e de baixa acidez, os bacilos termófilos formadores de esporos, alguns dos quais produzem esporos mais resistentes ao calor do que os esporos formados pela maioria dos anaeróbios estritos. Para os alimentos enlatados de baixa acidez, na opinião dos autores citados, o Bucillus steurotrermophilus e espécies correlatas merecem atenção especial: são microrganismos responsáveis pela alteração dos enlatados conhecida por "flat-sour" e muitas vezes nâo são identificados quanto à espécie pelo bacteriologista alimentar, mas tāo somente enquadrados como pertencentes ao grupo $B$. steurothermophilus.

Os trabalhos de AMAHA \%, relativos alos fatores que interferem sobre a resistencia térmica dos esporos bacterianos, endossam plenamente a idéia de que alguns anaeróbios estritos são capazes de produzir esporos altamente resistentes ao calor. Relativamente à deterioração dos alimentos enlatados, REED e col. 1: classificam os microrganismos responsáveis em dois grupos bem definidos: mesofílico e termofílico

Dos termófilos, os mais importantes são os microrganismos sacarolíticos não produtores de gás sulfídrico; o Clostridium thermosuccharolyticum é geralmente considerado como a espécie tipo deste grupo, no qual estão incluidos os germes capazes de fermentar grande variedade de hidratos de carbono, com grande quantidade de gás, sobretudo o dióxido de carbono e o hidrogênio. Esta condição leva as latas sanitárias que contém produtos deteriorados por essa via a apresentarem-se "inchadas" (ou "estufadas") e com odor butirico ("a queijo").

Os anaeróbios termofilicos produtores de esporos e de gás sulfídrico são os respon- 
sávejs pela "deteioração sulfurosa" dos alimentos cárneos enlatados. TOWNSEND e col. 16i, ao considerarem o Clostridium niyrificans como a espécie-tipo do grupo, incluem nele os germes proteolíticos, produtores de $\mathrm{H}_{2} \mathrm{~S}$ em grandes quantidades. Como o gás sulfídrico é solúvel nos produtos cárneos enlatados, as latas com alimentos deteriorados geralmente apresentam-se chatas (não estufaclas"), enquanto o produto mostra"-se enegrecido, devido à reação do gás com o ferro. Ná opinião de STUMBO 15, a deterioração dos enlalados por intermédio destas bactérias é relativamente rara, por dois motivos: primeiro, a incidência de seus esporos na maioria das linhagens são pouco resistentes ao calor, quando comparados com os esporos dos aneróbios termofílicos sacarolíticos e com os anaeróbios termofílicos produtores de "flat-sour".

Deve-se considerar, a seguir, os microrganismos anaeróbios mesofílicos formadores de esporos. Pelo que significa para a saúde pública, o Clostridium botulinum deve ser considerado o prototipo do grupo, sendo numerosíssimos os trabalhos com este microrganismo "i, ${ }^{11},{ }^{18}$. Os subtipos $A$, $\mathrm{B}$ e $\mathrm{E}$ do Clostridium botulinum são tidos como os mais importantes, sendo que os esporos dos tipos A e B sāo considerados como mais termo-resistentes do que os esporos do tipo $\mathrm{E}$, porisso, objetos de maior preocupação na esterilização dos alimentos enlatados. Outros microrganismos proteolíticos ou putrefativos frequentes como causadores de deterioração dos alimentos semi-ácidos ${ }^{8}, 13$ são o $\mathrm{Cl}$. putrificum, o $\mathrm{Cl}$. histolyticum, o $\mathrm{Cl}$. bifermentans, o Cl, sporoyenes e espécies correlacionadas. Entretanto, os processos destinados a assegurar um alto índice de segurança com relação ao $\mathrm{Cl}$ botulinum, sāo plenamente eficientes para prevenir a deterioração por esses microrganismos.

Paralelamente às informações relativas às características térmicas dos diferentes grupos e estirpes de microrganismos incriminados como agentes de deterioração dos alimentos cárneos enlatados, deve-se atentar também para outros fatores que modi- ficam a resistência das bactérias as altas temperaturas, desde os fatores intrínsecos aos microrganismos, como a hereditariedade, quanto aos extrínsecos, como a concentração salina e a presença de substâncias protetoras. YOKOYA ${ }^{19}$ reviu detalhadamente esses fatores, concluindo que sua influência sobre os esporos e as células vegetativas das bactérias são tanto ou até mais importantes do que as características térmicas inerentes aos próprios microrganismos. Em outro trabalho, esse mesmo autor 2" discute as fórmulas básicas empregadas no cálculo da esterilização dos alimentos enlatados, pelo processo matemático, as quais são usadas para organizar gráficos, tabelas e equações de uso prático no cálculo de processamento, mormente no que se refere às temperaturas letais, ou seja, as temperaturas que provocam a morte das bactérias.

O objetivo do presente estudo foi o de determinar os microrganismos responsáveis pela deterioração de um produto cárneo enlatado de baixa acidez, ou seja, a presuntada. Procurou-se identificar a carga mais comum de deterioraçāo, isto é, um su-processamento ou um vazamento pós-processamento. Para tanto, foram escolhidos quatro grupos de germes: dois tipicamente esporulados (Bucillus e Clostridium), que refletem muito bem a deterioraçāo por sub-processamento, e dois nāo esporulados (coliformes e enterococos), habitantes normais do intestino do homem e dos animais e, consequentemente, valiosos índices de contaminação por vazamentos da lata sanitária.

\section{E TODOLOG I A}

O material utilizado no presente trabalho foi representado por 210 latas de presuntada, colhidas em três frigoríficos 10calizados no Municipio de São Paulo, e que haviam sido condenadas pelo serviço de fiscalização sanitária. Pelo periodo de cento e oitenta dias, procedeu-se à colheita das amostras, analisando-se cerca de dez amostras por semana. Essa amostragem correspondeu a $7,57 \%$ do total de 
2771 iatas condenadas por "bombeamento" ("estufadas" ou "inchadas"), nesse mesmo período.

Chegadas ao laboratório, as latas sanitárias foram analisadas bacteriologicamente seguindo-se as técnicas contidas nos "Recommended Methods for the Microbiological Examination of Foods" t, obedecendo-se rigorosamente os cuidados preconizados para a identificação, análise das condiçōes e abertura do recipiente. A escolha dos meios de cultura recaiu, para os germes do grupo coliforme e enterococo, no "Brilliant Green Bile 2\% Broth" (Difco B-7), confirmado pelo "Levine E. M. B. Agar" (Difco B-5) e no meio de LITSKY e col. ${ }^{10}$, modificado por RAJ e col. 11, em suas fases presuntiva e confirmativa, respectivamente

Para a pesquisa dos microrganismos pertencentes aos gêneros Bacillus e Clostridium utilizaram-se dois meios de cultura: o caldo triptona-glicose e o caldo de figado, segundo a técnica preconizada por STUMBO ${ }^{15}$, que permitiram distinguir os germes do grupo Bacillus (mesófilos e termófilos aeróbios estritos e anaeróbios facultativos), dos germes do grupo Clostridium (mesófilos e termófilos anaeróbios estritos). A prova da catalase foi utilizada, ainda, para referendar a distinção entre os dois grupos.

A interpretação numérica dos resultados foi conseguida, para os quatro grupos de microrganismos, pelo método estatístico do número mais provável ${ }^{3}$.

\section{RESULTADOS E DISCLISSAO}

O Quadro n. 1 mostra a quantidade de resultados positivos para os microrganismos dos grupos coliforme, enterococo, $B(t-$ cillus sp. e Clostridium sp. Desse quadro foram dispensadas as amostras que acusaram negatividade para os quatro grupos.

Os percentuais de ocorrência de positivos, tomando-se por base as duzentas e dez amostras analisadas, encontram-se detalhadas no Quadro n. 2.
QU A D R O 1

Ocorrência de germes dos grupos Coliforme Enterococo, Bacillus e Clostrialium em 210 amostras de presuntara enlatada, rejeitadas pelo Serviço de Fiscalização Sanitária.

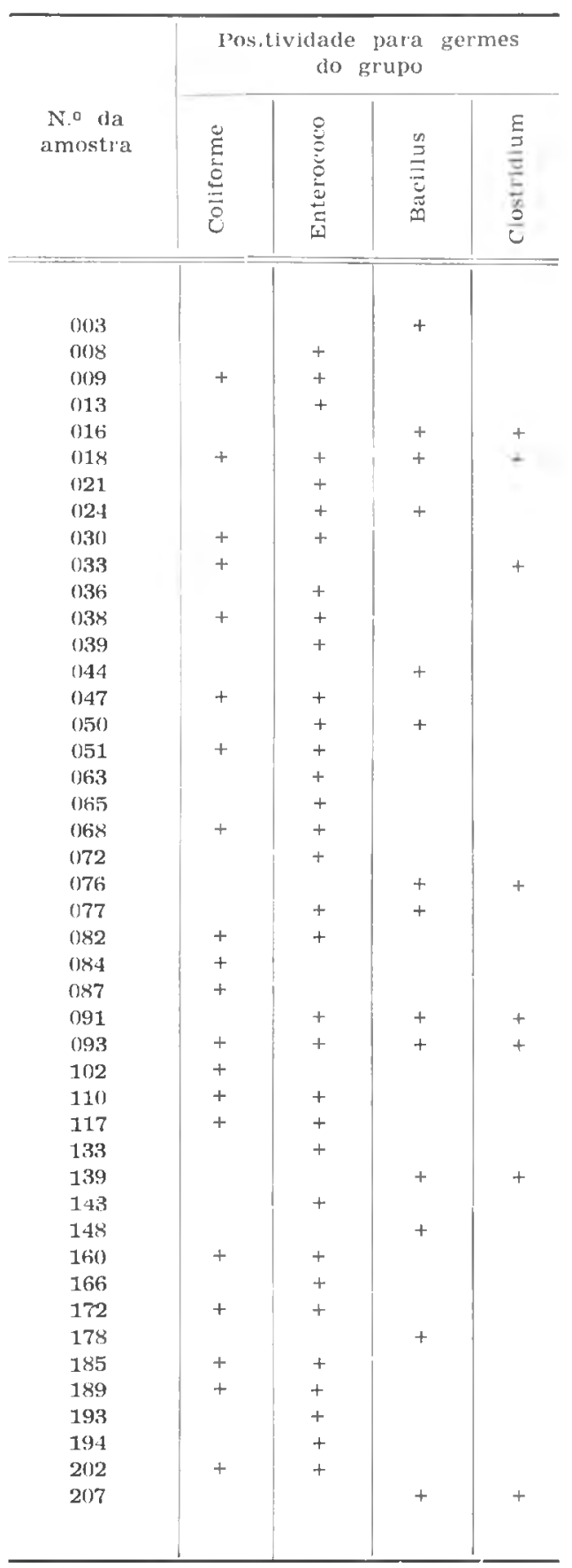


Q LA D R O 2

Percentuais de ocorrencia de germes dos grupos coliforme, enterococo, Bacillus e Clostridium, em 210 amostras de presuntada enlatada, rejeitadas pelo Servico de Fiscalizaçāo Sanitâria.

\begin{tabular}{|c|c|c|}
\hline $\begin{array}{l}\text { Microrganismo } \\
\text { Pesquisado }\end{array}$ & Froquência & Irecentual \\
\hline $\begin{array}{l}\text { Coliformes } \\
\text { Enterococos } \\
\text { Barillus sp. } \\
\text { Clostridium sp. }\end{array}$ & $\begin{array}{r}20 \\
33 \\
14 \\
8\end{array}$ & $\begin{array}{r}9,52 \\
15,71 \\
6,66 \\
3,80\end{array}$ \\
\hline
\end{tabular}

A observaçāo minuciosa do Quadro n.í 1 permite depreender algumas informaçōes importantes acerca do tipo da contaminação envolvida com a deterioração do produto. Assim, nem sempre foi possivel caracterizar decisivamente a presença somente dos grupos coliforme-enterococo ou Bacillus-Clostridium . Algumas vezes ocorreram contaminaçōes mistas: coliforme-enlerococo-Bucillus, enterococo-Bacillus, coliforme-Clostridium, enterococo-Bacillus-Clostridium e, mesmo, coliforme-enterococoBucillus-Clostridium. Estes achados referendam as opiniōes de HERSOM \& HULLAND?, REED e col. ${ }^{12}$ e STUMBO ${ }^{10}$. unânimes ao considerarem bastante diversificadas as estirpes microbianas responsáveis pela deterioração dos alimentos cárneos enlatados e processactos pelo calor. Ora, se um recipiente "respirar", ainda que seja apenas por momentos, bactérias podem ser introduzidas com a água ou o ar contaminados. É muito mais provável a sua penetraçāo com água contaminada do que com o ar, pois na maioria dos casos, as aberturas que determinam o vazamento sāo suficientemente prquenas para fil- trar poeiras com bactérias provenientes do ar. Isto, porém, náo ocorre com as bactérias em suspensão na água. Porisso e ainda em consequiência das pressōes nas costuras das latas e nas tampas dos frascos durante a operaçāo de resfriamento, é muito mais plausivel que as bactérias tenham acesso durante o resfriamento ou logo depois, enquanto os recipiente ainda estejam úmidos. Esta ripótese parece demonstrada pelos resultados do presente trabalho, onde foi detectada, na maioria das amostras, uma contaminaçāo mista, representada por germes dos grupos coliforme e enterococo e dos grupos Bacillus e Clostridium. Ainda nesse sentido, são significativas as observações de CAMERON \& ESTY 5, ao afirmar que "quantidades diminutas de água contaminada podem determinar a deterioraçāo; por exemplo, se a ảgua estiver contaminada com $1 \mathrm{mi}$ lhão de bactérias por mililitro, um milionésimo de mililitro penetrando no recipiente será suficiente para determinar a deterioraçāo".

A análise do Quadro n.á 2 também apresenta algumas evidências interessantes: primeiro, a supremacia dos grupos coliforme-enterococo sobre os grupos BucillusClosiridium, o que faz crer numa maior incidência de deterioração por vazamento do que por sub-processamento, em concordância com REYNOLDS \& LICHTENSTEIN 13; segundo, a supremacia do grupo Bacillus sobre o grupo Clostridium, referendando a maior resistência térmica dos bacilos termófilos formadores de esporos e anaeróbios facultativos, endossando as conclusōes de YOKOYA ${ }^{19}$; terceiro, a supremacia do grupo enterococo sobre o grupo coliforme, tornando taxativa, como também considera RAJ 11, a maior resistência ao calor dos estreptococos pertencentes ao grupo D de Lancefield, quando comparados com os microrganismos pertencentes ao grupo coliforme 


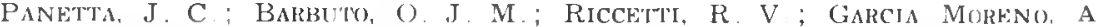
Occurrence of microrgunisms responsuble for deterioration of a meat suburoduct of low acidity. Rev. Far. Med. vet. Zootec. Iniv. S. Paulo, 13(1):241-47, 1976

Summary: In the present puper it was studied the couse of contumination of corned beef a meut subproduct of low aridity, wiere anulysed 210 samples. The following agents were searched: Closiridium _ $3.8 \%$ : Bacillus - 6.66\%: Coliforms - 9.52\%; Enterococos - $15,71 \%$

Knowing that the present agents of the group Bacillus and Clostridium is a marker of deterioration by subprocessing and the detection of Coliforms and Enterococci is an index of leakage from sunitury cans the results obtained allowed to conchude that leakuge of sanitary cans is the most frequent callse for the mutrefactive alterations found in these products.

UNITERM: Canned food spoiluge*; Canned meat *

\section{RFFERENCIAS BIBIIOCRAEICAS}

1 - ALLEN M B. The thermophilic derobic sporeforming bacteria. Bacteriol. Rev., 17:125, 195.3

2 AmAlta, M, Fachors affecting heatdestruction of bacterial spores. INTERNATIONAI. CONGRESS OF CANNED FOODS 4. Berlin 1961 procoetings.

3. AMERICAN PIBLIC HEALTI ASSOCIATION Standard methods for the examination of water, sewage and inciustrial wastes. 10th ed. New York. 1955. p. 375-87

4 - AMERICAN PUBLIC HEALTH ASSOCIATION Recommended methods for the microbiological examination of fonds. New York, 1958. 207 p.

5 - CAMERON, E.J, \& ESTY, J.R. Comments on the microbiology of spoilage in canned foods. Foud Res., s 549. 1940 .

(i) FILER, ( . : ROCiERS, I, \& WYNNE, E.S. Agar concentration in Counting crostridium colonies. Appl. Mi (robiol, 15(1):55-57, 1967.

7 FRAZIFR, W.C. Fond miembiologly New York, Ma Gaw-llill, 1958 472 ()

$\therefore$ IIERSCIIDOERFFR. S.M. Quality rontrol in the rood industry london.

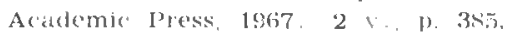
140
9 HERSOM A.C \& HULLAND E U Canned foods. An Introduction to their Microbiology. 5 th ed. New York, Chem. ['ubl., 1964. 291 b.

10. IITSKY W et al A neu medium for the detection of enterococri in water, Amer, J pull. Hlh, $43(7)$ $873-9, \quad 1953$

11 - RAJ II. Detection and enumeration of secal indicator organisms in frozen sea foods. II. Enterococei Appl. Mirrobiol., 9(4):295-303, 1961

12 -.. REED, I.M ; BOHRER, C.W.; CANERON, J.E. Spore destruction rate studies on organism of significance in the processing of canned foods Food Res. 16:383 1951

13 REYNOLDS, 1 \& \&ICHTENSTEIN 11. Evaluation of heat resistance datil for bacterial spores. Bacternl. Rels.s. $16: 126-35, \quad 1952$

14 SNIDDFN, B.II.\& ILCHOWICH, R.V Growth and sporulation of $\mathrm{Cl}$. botulinum type $\mathrm{E}$ in chemically defined medial. Michigan, 1968. I Michigan, Agricultural Experiment Station. Journal Article no $384 \mathrm{~s})$

15 STLMi30, C. R. Thermobateriology in food processing. London. Aroblemil' l're'ss, 1965 . 236 1 .

16 TOWSENI) C T : SOMERS. I I : I,AMIS. F.C.; OLSON, N.A. A laboratory 
manual for the canning industry. 2nd ed. Washington, D.C., National Canners Association Research I abolatories, 1956

17 - VALGHN, R.II.: KREUI.EVITCH. I.H. MERCER, W.A. Spollage of canned foods raused by the Bacillus macerans - polymyxa group of bac'teria. Food Res., 17:560, 1952.

18-- WYNNE, E.S.: SCIMJEDING, W.R.: DAYE, G.T. A simplified medium for counting Clostridium spores. Food Res., 20:9-12, 1955.
19 - YOKOYA, F. Fatores que influem 11a "morte" das bactérias a altas temperaturas. Boletim do Centro Tropical de Pesquisas e Tecnologia de Alimentos, (11):2-26, 1967.

20 - VOKOYA, F. Fundamentos da esterilizacāo dos alimentos enlatados. Boletim do Centro Tropical de Pesquisas e Tecnologia de Alimentos. (16) :1-32, 1968 .

Recebido para publicaça em 15-3-76 Aprovado para publicasão em $25-3-76$ 